\title{
Effects of weather variation on waterfowl migration: lessons from a continental-scale generalizable avian movement and energetics model
}

\author{
Kevin Aagaard ${ }^{1}$, Eric Lonsdorf ${ }^{2}$, and Wayne Thogmartin ${ }^{3}$ \\ ${ }^{1}$ Colorado Parks and Wildlife \\ ${ }^{2}$ University of Minnesota \\ ${ }^{3}$ US Geological Survey
}

March 17, 2021

\begin{abstract}
We developed a nonbreeding period continental-scale energetics-based model of daily waterfowl movement to predict year-specific migration and overwinter occurrence. The model approximates energy-expensive movements and energy-gaining stopovers as functions of metabolism and weather, in terms of temperature and frozen precipitation (i.e., snow). The model is a Markov process operating at the population level and is parameterized through a review of literature. We examined model performance against 62 years of non-breeding period daily weather data. The average proportion of available habitat decreased as weather severity increased, with mortality decreasing as the proportion of available habitat increased. The most commonly used nodes during the course of the nonbreeding period were generally consistent across years, with the most inter-annual variation present in the overwintering area. Our model revealed that the distribution of birds on the landscape changed more dramatically when the variation in daily available habitat was greater. The main routes for avian migration in North America were predicted by our simulations: the Eastern, Central, and Western flyways. Our model predicted an average of $77.4 \%$ survivorship for the nonbreeding period across all years (range $=76.4-78.4 \%$ ), with lowest survivorship during the fall, intermediate survivorship in the winter, and greatest survivorship in the spring. We provide the parameters necessary for exploration within and among other taxa to leverage the generalizability of this migration model to a broader expanse of bird species, and across a range of climate change and land use/land cover change scenarios.
\end{abstract}

\section{Hosted file}

Generalized Avian Movement and Energetics Model_v10.pdf available at https://authorea. com/users/402029/articles/513945-effects-of-weather-variation-on-waterfowl-migrationlessons-from-a-continental-scale-generalizable-avian-movement-and-energetics-model 